\title{
Removal of Nitrite Ions from Aqueous Solutions Using Conducting Electroactive Polymers
}

\author{
R. Ansari*, N. Khoshbakht Fahim and A. Fallah Delavar
}

Chemistry Department, University of Guilan, Rasht, Iran

\begin{abstract}
This paper deals with a new application of polypyrrole (PPy) and polyaniline (PAni) electroactive polymers synthesized chemically, coated on sawdust and then used for removal of $\mathrm{NO}_{2}{ }^{-}$ions from aqueous solutions. Adsorption studies were performed using both batch and column systems at room temperature. The effects of some important parameters such as initial concentration, adsorbent dosage, and contact time on the uptake of $\mathrm{NO}_{2}^{-}$ions were also investigated. PPy and PAni conducting electroactive polymers were found to be effective adsorbents for the uptake of nitrite ions from aqueous solutions. Adsorption studies have shown that $\mathrm{pH}$ of the nitrite solution has an important influence on the nitrite ion uptake. In order to find out the possibility of the frequent use of the adsorbent, desorption study was also carried out in this investigation.
\end{abstract}

Key Words: Nitrite ion, polypyrrole, polyaniline, sorption, desorption.

\section{INTRODUCTION}

Nitrite ion is one of the most important wide-spread contaminants of aqueous environment and serves as a significant indicator of natural water quality. The increasing level of nitrite in surface or ground waters results mainly from agricultural application of fertilizers as well as from many industrial processes [1].

Removal of nitrite ions from waters has received increasing attention in recent years because of their potential harmful impact on human health. $\mathrm{NO}_{2}{ }^{-}$is highly toxic to certain species of fish. Nitrite ions enter the bloodstream through gills by a mechanism that normally transports chloride [2]. After entering the bloodstream, $\mathrm{NO}_{2}{ }^{-}$oxidizes iron in the hemoglobin molecule from ferrous state $\left(\mathrm{Fe}^{2+}\right)$ to the ferric state $\left(\mathrm{Fe}^{3+}\right)$. The resultant product, called methemoglobin, is incapable of reversibly binding with oxygen, so exposure to $\mathrm{NO}_{2}^{-}$causes respiratory distress because of the loss in oxygen- carrying capacity of blood.

Nitrite is one of the major components of wastewater from nuclear power production and involved in the corrosion and bacterial process known as the nitrogen cycle. Nitrite and its salts have many industrial and commercial applications. Sodium nitrite is a food additive that has been used for decades to preserve meat, poultry and fish. When used alone or in conjunction with sodium nitrate, nitrite gives cured meats their characteristic reddish-pink color, flavor and texture. The allowed concentration of nitrite in drinking water and food reported by the public health service is $0.06 \mathrm{mg} \mathrm{L}^{-1}$ [3]. Elevated concentrations of nitrite can be found in water receiving nitrogenous effluents, in various hypoxic environments or in effluents from agricultural application of fertili-

*Address correspondence to this author at the Chemistry Department, University of Guilan, Rasht, POB 41335-1914, Iran; Fax: 0098-0131-3233262; E mail: ransari@guilan.ac.ir zers and industries producing metals, dyes and celluloid [4]. Ion exchange, reverse osmosis, electrodialysis, distillation and activated carbon adsorption are processes that have been employed for uptake of nitrite from drinking water supplies [4], but these processes are expensive and a brine of difficult management is generated.

Recently, we have found that polypyrrole and polyaniline conducting electroactive polymers (CEPs) can be employed for removal of some toxic metal ions from aqueous solutions $[5,6]$. Synthesis of these reactive and functional polymers have been carried out by either electropolymerization at a conductive substrate (electrode) through the application of an external potential, or chemical polymerization in solution by the use of a chemical oxidant [7-10]. The overall polymerization reaction of pyrrole can be shown as the following (Fig. 1).

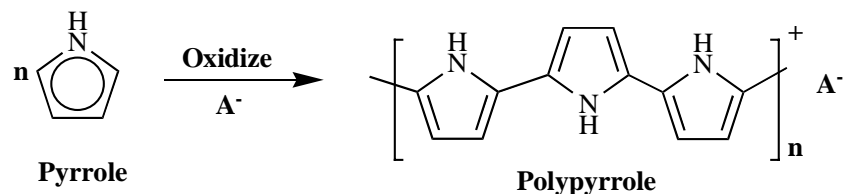

Fig. (1). Overall polymerisation reaction of polypyrrole.

Where, the $\mathrm{A}^{-}$(termed as dopant or counterion) is the anion of oxidant in monomer solution or reduced product of oxidant. The value of $\mathrm{n}$ has been determined to be between 2.2 and 2.4. The level of oxidation of ppy is $0.25-0.32$ per pyrrole unit, depending on the type and the charge of the incorporated anion, corresponding to one anion for every 3-4 pyrrole units in order to achieve electroneutrality, and this makes up 30-40\% of the final weight of the polymer [10]. However, chemical polymerization remains of interest for processing purposes, because it may be easier to scale up this batch process for bulk production. 
The redox behavior of PPy electroactive polymers have been shown in Fig. (2), for cases where the counterion $\left(\mathrm{A}^{-}\right)$is able to freely leave the polymer matrix and where it is immobilized within the CEP matrix. In this representation, $\mathrm{A}^{-}$is necessary to balance the charge on the polymer backbone, Anion movement predominates in cases where small mobile dopant, e.g., $\mathrm{Cl}^{-}$, is used $[11,12]$. If large anion dopants such as polyelectrolytes are employed, cation movement will predominate.
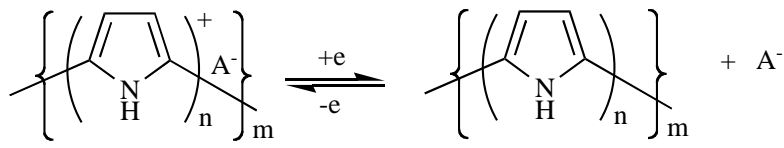

AND/OR

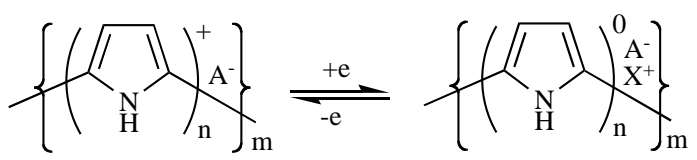

Fig. (2). The electrodynamic character of polypyrrole.

Polyaniline (PAni) is another class of conducting electroactive polymers that has attracted a great deal of attention in recent years [13]. It is now accepted to have the general polymeric structure as shown in Fig. (3). It differs from most of the other inherently conducting polymers, such as polypyrroles (PPys) and polythiophenes, in that it possesses three readily accessible oxidation states. These range from the fully reduced $(y=1)$ Leucoemeraldine state to the half oxidized $(y=0.5)$ Emeraldine form to the fully oxidized $(y=0)$ Pernigraniline state. Emeraldine is the state with highest conductivity.

PAni is unique among inherently conducting polymers in that it can be rapidly converted between base and salt forms by treatment with acid or base. These reversible redox and $\mathrm{pH}$ switching properties, together with the electrical conductivity of its emeraldine salt (ES) form (Fig. 4), its easy synthesis from aqueous solutions, processibility, and its high thermal and environmental stability, have led to its becoming the most extensively studied conducting organic polymer over the past decade, and a wide range of potential applications are currently being developed.

Almost all the previous applications of conducting polymers rely on electrical and electrochemical behaviors which are the most important properties of these polymers. This paper deals with a new application of PPy and PAni conducting polymers for removal of toxic anions such as nitrite ion. The removal of nitrite ion by these polymers seems to be mostly due to the interesting ion exchange or redox properties of the employed polymers.

\section{EXPERIMENTAL}

\subsection{Materials and Equipments}

All chemicals used were analytical reagents grade and prepared in deionized water. Pyrrole and aniline were obtained from Merck and distilled before use. Sodium nitrite $\left(\mathrm{NaNO}_{2}\right)$ solution with the concentration of $100 \mathrm{mg} \mathrm{L}^{-1}$ (ppm) vs. nitrite $\left(\mathrm{NO}_{2}^{-}\right)$was prepared and used as stock solution.

\subsection{Preparation of PPy/SD and PAni/SD}

The polymers were synthesized directly on the surface of the sawdust, which was previously soaked in monomer solutions $(0.2 \mathrm{M})$ by slow addition of chemical oxidants $\left(\mathrm{FeCl}_{3}\right.$ for PPy and $\left(\mathrm{NH}_{4}\right)_{2} \mathrm{~S}_{2} \mathrm{O}_{8}$ for PAni) at room temperature. Sawdust sample (SD) obtained from walnut wood obtained from a local carpentry workshop. It was first washed copiously with doubly distilled water and finally dried at temperature about $80 \mathrm{C}$ for $2 \mathrm{~h}$. In order to have uniform coating, after drying, they sieved before use (using ASTM standard sieve 35-50 $\mu \mathrm{m}$ ). Sawdust samples were first soaked in monomer solution for 2 hours at room temperature. The mixture was filtered and then the oxidant solution was added onto the SD gently. Polymerization was carried out on the surface of SD immediately after addition of the oxidant solution. Sawdust coated or modified by polymers (termed as PAni/SD and PPy/SD) was filtered, washed with copious distilled water, then dried at temperature about $60{ }^{\circ} \mathrm{C}$ (in an oven), and sieved again before use. The details can also be found in our previously published paper [14].

\subsection{Determination of Nitrite Ion $\left(\mathrm{NO}_{2}^{-}\right)$}

Determination of nitrite ion was carried out spectrophotometrically, using a calibration curve employing Beer's Law. In determination of nitrite ion, a Griess reagent was used [15]. This reagent consists of aqueous solution of $1.0 \%$ sulfanylamide and $0.1 \%$ naphthylethylendiamine di-hydrochloride in $2.5 \% \mathrm{H}_{3} \mathrm{PO}_{4}$ to form a stable chromophore absorbing at a wavelength of $525 \mathrm{~nm}$. The calibration curve was obtained from standard solutions of nitrite $\left(\begin{array}{lll}0.0 & -1.0\end{array}\right.$ ppm) $\left(\lambda_{\max }=525 \mathrm{~nm}\right)$. A single beam Perkin-Elmer UV-V is

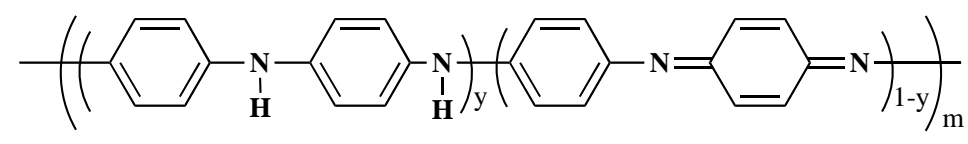

Fig. (3). General structure of polyaniline (PAni).

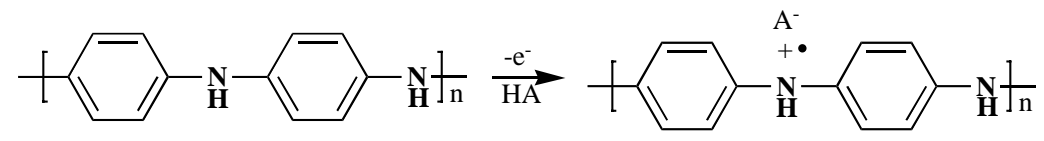

Fig. (4). Emeraldine salt (ES) form of polyaniline. 
spectrophotometer with a $1 \mathrm{~cm}$ cell was used for analysis of anions and measuring all of the absorption data. A Metrohm $\mathrm{pH}$ meter (model 827) with a combined double junction glass electrode, calibrated against two standard buffer solutions at $\mathrm{pH} 4.0$ and 7.0, was used for showing $\mathrm{pH}$ values. Dilute $\mathrm{NaOH}$ and $\mathrm{HCl}$ solutions were used for $\mathrm{pH}$ adjustments.

All the experiments were carried out at least in triplicate. The results reported are the average of these measurements. The linear regression analysis was carried out for treatment of the data. The relative standard deviation (RSD) was less than $2.0 \%$ and the detection limit value, based on three times the standard deviation of the blank was $10 \mathrm{ppb}$.

\subsection{Sorption Experiments}

In batch experiment, a fixed amount of sorbents was treated with nitrite polluted solutions $(0-100 \mathrm{ppm})$ at room temperature. During each experiment, the solutions were agitated using a mechanical shaker. In column experiments, a glass column with dimensions of $1.0 \mathrm{~cm}$ diameter and 15 $\mathrm{cm}$ height was employed. $1.0 \mathrm{~g}$ sorbent (PPy/SD or PAni/SD) was packed in the column (bed volume $\sim 5 \mathrm{~cm}^{3}$ ), and then the anion solution was passed through the column with flow rate of $3 \mathrm{~mL} \mathrm{~min}{ }^{-1}$. The outlet solution was analyzed for residual or unadsorbed nitrite. The following equations were used to calculate the percentage of sorption and the amount of sorbed anion, respectively:

$$
\begin{aligned}
& \text { \%Sorption }=\frac{C_{0}-C_{e}}{C_{0}} \times 100 \\
& \frac{x}{m}=\frac{C_{0}-C_{e}}{m} \times V
\end{aligned}
$$

$\mathrm{C}_{0}$ and $\mathrm{C}_{\mathrm{e}}$ are the initial and equilibrium concentrations of the anion, respectively $\left(\mathrm{mg} \mathrm{L}^{-1}\right), \mathrm{x} / \mathrm{m}$ is the amount of anion sorbed onto unit amount of the adsorbent $\left(\mathrm{mg} \mathrm{g}^{-1}\right)$ at equilibrium, and $\mathrm{V}$ is the volume of the solution used in the adsorption experiment (L). All of the sorption experiments were carried out at room temperature. Since sorption percentage of nitrite ions by unmodified or uncoated sawdust (SD) was poor (less than 10\%), so all of our further adsorption studies were performed using modified sawdust (PPy/SD and PAni/SD).

\section{RESULTS AND DISCUSSIONS}

\subsection{Sorption of Nitrite Ion by PAni/SD and PPy/SD (Batch System)}

\subsubsection{Effect of Initial pH}

It is well known that $\mathrm{pH}$ of a solution strongly affects many adsorption processes depending on the nature of adsorbents and adsorbates. So it is very important to find out first the suitable $\mathrm{pH}$ value for any sorption process before investigation of other parameters. Since nitrite ion is unstable at $\mathrm{pH}<4$, all of the experiments related to nitrite were carried out at $\mathrm{pH} \geq 5$. In this experiment, $1.0 \mathrm{~g}$ dried sorbents (PAni/SD and PPy/SD) and sawdust as a blank were exposed separately to $25 \mathrm{~mL}$ of nitrite solution with concentration of $50 \mathrm{ppm}$ at different $\mathrm{pH}$ values (5-10). The results obtained for PAni/SD and PPy/SD are shown in Fig. (5). These results show sorption of nitrite ion decreases as $\mathrm{pH}$ of treated solution increases for PAni/SD because of an increase in basic property of polymer due to the decrease in $\mathrm{Cl}^{-}$exchange on the sites in polymers. Removal of nitrite ion using PPy and PAni based on the ion exchange property of these polymers can be shown as the following equations:

$$
\begin{aligned}
& \mathrm{PPy}^{+} \mathrm{Cl}^{-} / \mathrm{SD}_{\text {(solid) }}+\mathrm{NO}_{2}^{-} \text {(solution) } \\
& \mathrm{Cl}_{\text {(solution) }}^{-} \\
& \mathrm{PAni}^{+} \mathrm{Cl}^{-} / \mathrm{SD}_{\text {(solid) }}+\mathrm{NO}_{2}^{-} \text {(solution) } \\
& +\mathrm{PPy}^{+} \mathrm{NO}_{2}{ }^{-} / \mathrm{SD}_{\text {(solid) }}+ \\
& +\mathrm{Cl}_{\text {(solution) }}^{-}
\end{aligned}
$$

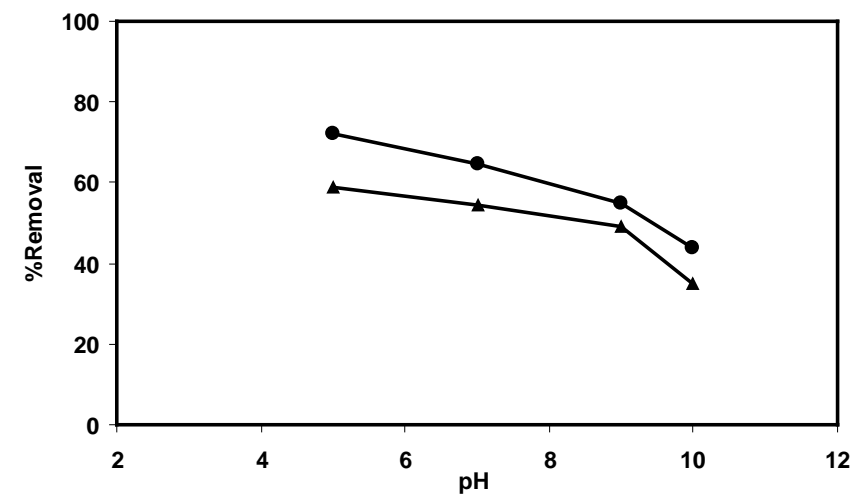

Fig. (5). Effect of $\mathrm{pH}$ for the removal of nitrite ion using: PPy/SD• and PAni/SD $\mathbf{A}$

The rate of nitrite removal seems to be dependent on the molecular weight (MW) of the polymer and the level of polymer oxidation. Higher molecular weight and highly doped polymer possess more anions or counterions available for exchanging. However, importance of some other reasons such as strong interactions of nitrite ion with the amine and imine groups in the polymers and also the redox reactions between the electroactive adsorbate (nitrite ion) and adsorbent (PPy or PAni) can not be ignored. More investigation is needed for the achievement of precise conclusions.

\subsubsection{Effect of Initial Concentration of Nitrite Solution (Batch System)}

In this section, $1.0 \mathrm{~g}$ of sorbents (PAni/SD and PPy/SD) were placed in contact with $25 \mathrm{~mL}$ of different concentrations of nitrite for one hour at $\mathrm{pH}=5$ (as optimum $\mathrm{pH}$ value). The results obtained are summarized in Table $\mathbf{1}$ and the graphical forms of the effect of initial concentration have also been shown in Fig. (6).

Table 1. Effect of Initial Nitrite Ion Concentration on Sorption Percentage (Batch System)

\begin{tabular}{|c|c|c|c|c|c|}
\hline \multirow{2}{*}{ Sorbent } & \multicolumn{5}{|c|}{$\mathbf{C}_{\mathbf{0}}\left(\mathbf{m g ~ L}^{-1}\right)$} \\
\cline { 2 - 6 } & $\mathbf{1 0}$ & $\mathbf{2 5}$ & $\mathbf{5 0}$ & $\mathbf{8 0}$ & $\mathbf{1 0 0}$ \\
\hline \hline PPy/SD & 76 & 73 & 72 & 70 & 69 \\
\hline PAni/SD & 68 & 69 & 60 & 41 & 40 \\
\hline
\end{tabular}


As the results obtained in this investigation show, with increasing the initial concentration of nitrite ion $\left(\mathrm{C}_{0}\right)$, removal percentage is decreased slightly in the case of $\mathrm{PPy} / \mathrm{SD}$ then becomes constant. However; total amount of metal sorption $(\mathrm{x} / \mathrm{m})$ for both adsorbents are increased gradually (Fig. 6).

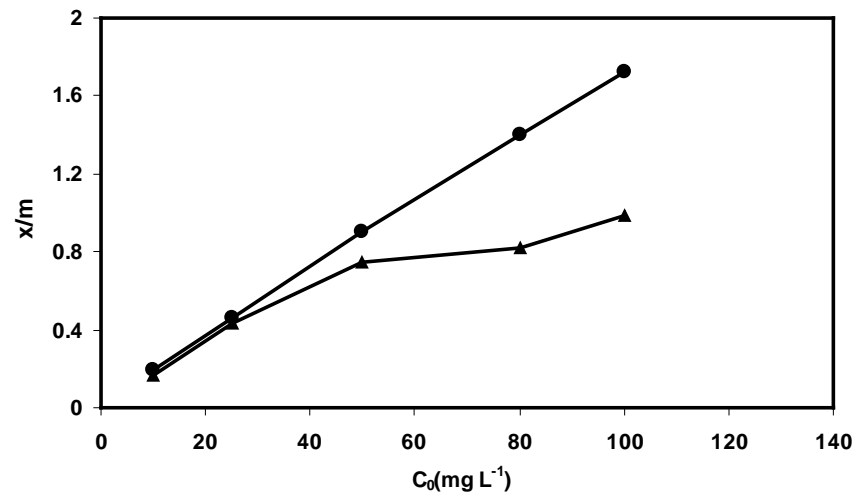

Fig. (6). Effect of initial nitrite concentration on its sorption onto $\mathrm{PPy} / \mathrm{SD} \bullet$ and PAni/SD $\boldsymbol{\Delta}$.

As our data show, $\mathrm{PPy} / \mathrm{SD}$ is a more efficient adsorbent compared to PAni/SD. Increase in the total uptake of nitrite ion using PPy/SD could be explained by the fact that an increase in nitrite concentration accelerates the diffusion of adsorbate ions from the solution onto adsorbents, due to the increase in the driving force of the concentration gradient.

\subsubsection{Effect of Exposure Time}

In this investigation, $1.0 \mathrm{~g}$ of sorbents (PAni/SD and PPy/SD) were exposed to $25 \mathrm{~mL}$ of nitrite ion solutions with concentration of $50 \mathrm{ppm}$ at $\mathrm{pH}=5$ at different equilibration times (10-60 min). Exposure of adsorbents to nitrite ion were accompanied by gentle shaking the samples at room temperature. The results from the removal obtained from the analysis of unsorbed nitrite ion in solution are shown in Fig. (7), which indicate removal of nitrite using PPy/SD occurs quickly and is not a very time dependent process.

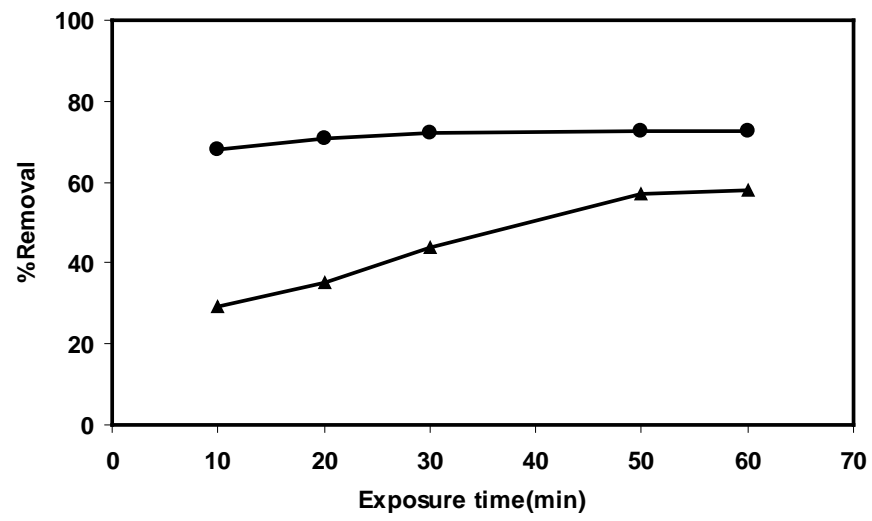

Fig. (7). Effect of exposure time on nitrite sorption percentage by $\mathrm{PPy} / \mathrm{SD} \bullet$ and PAni/SD $\boldsymbol{\Delta}$.

As the data in Fig. (7) also show the amount of time required before the adsorption process attains constant and equilibrium is reached is longer for PAni/SD compared to $\mathrm{PPy} / \mathrm{SD}$.

\subsubsection{Effect of Sorbent Dosage}

The adsorption study was also carried out by using adsorbent dosage over the range 0.1 to $1.0 \mathrm{~g}$ at $25 \mathrm{~mL}$ of $50 \mathrm{mg}$ $\mathrm{L}^{-1}$ of nitrite ion solutions and $\mathrm{pH}$ value about 5 . The effect of variation of sorbent dosage on the removal of nitrite by PAni/SD and PPy/SD is shown in Fig. (8). As our results show (Fig. 8), the removal percentage of nitrite ions increase rapidly with increase in the dose of PPy/SD to a certain value and then remained constant. This is due to the greater availability of exchangeable sites.

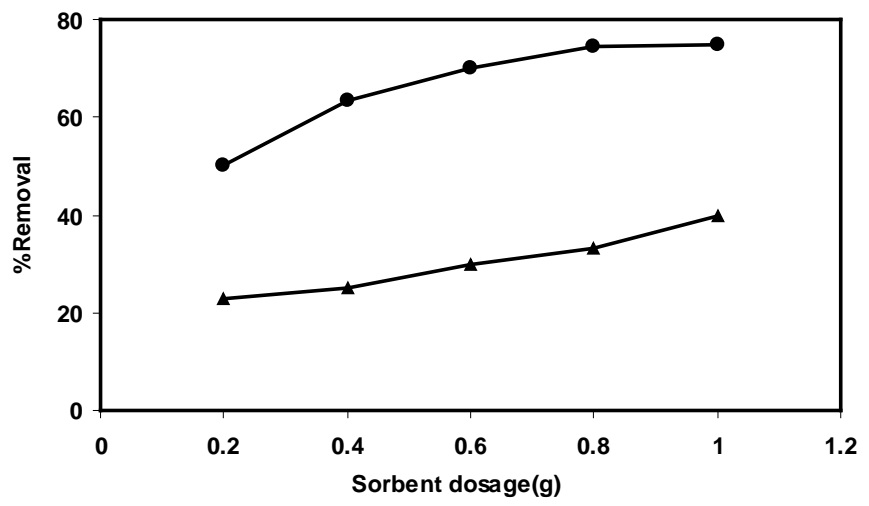

Fig. (8). Effect of sorbent dosage on nitrite sorption percentage by $\mathrm{PPy} / \mathrm{SD} \bullet$ and PAni/SD $\boldsymbol{\Lambda}$.

According to the data obtained in this part of our study, $\mathrm{PPy} / \mathrm{SD}$ was found to be more efficient sorbent than PAni/SD for nitrite ion removal under the same sorbent dose. Based on Fig. (8), the maximum adsorption capacity was exhibited at $1.0 \mathrm{~g}$ for both adsorbents.

\subsubsection{Effect of Initial Concentration (Column System)}

For performing this experiment, $1.0 \mathrm{~g}$ of PAni/SD and PPy/SD packed in a glass column (fixed bed depth of $5 \mathrm{~cm}$ ), and then nitrite solutions with different concentrations (10$100 \mathrm{ppm})$ and same volumes $(25 \mathrm{~mL})$ were passed through the column with constant flow rate $\left(3 \mathrm{~mL} \mathrm{~min}{ }^{-1}\right)$ at $\mathrm{pH}=5$ (optimum $\mathrm{pH}$ value). The data obtained from this investigation is summarized in Table $\mathbf{2}$.

Table 2. Effect of Initial Concentration of Nitrite Ion on Sorption Percentage in Column System

\begin{tabular}{|c|c|c|c|c|c|}
\hline \multirow{2}{*}{ Sorbent } & \multicolumn{5}{|c|}{$\mathbf{C}_{\mathbf{0}}\left(\mathbf{m g ~ L}^{-1}\right)$} \\
\cline { 2 - 6 } & $\mathbf{1 0}$ & $\mathbf{2 5}$ & $\mathbf{5 0}$ & $\mathbf{8 0}$ & $\mathbf{1 0 0}$ \\
\hline \hline PPy/SD & 70 & 69 & 61 & 58 & 56 \\
\hline PAni/SD & 61 & 59 & 52 & 35 & 30 \\
\hline
\end{tabular}

As our data obtained from this investigation show that an increase in initial concentration of nitrite ions, resulted in a gradual decrease in its removal percentage for both adsorbents. In other words, currently introduced adsorbents are more effective at low initial concentrations of nitrite ions when continuous or column adsorption system is used. 


\subsubsection{Desorption Study (Column System)}

The regeneration of adsorbents, as well as recovery of adsorbed material, is very important from application point of view. Desorption studies will also help to elucidate the nature adsorption process. In this study, $1.0 \mathrm{~g}$ of sorbent (PAni/SD and PPy/SD) was first treated with $25 \mathrm{~mL}$ of $\mathrm{NO}_{2}{ }^{-}$ ion with concentration $50 \mathrm{mg} \mathrm{L}^{-1}$ at $\mathrm{pH}=5$. Desorption experiments in column system was conducted using dilute $\mathrm{NaOH}$ solution $(0.1 \mathrm{M})$ as the desorption agent. Desorption percentage was then calculated from the following expression:

$\%$ Desorption $=\frac{\text { Amount of anion desorbed }}{\text { Amount of anion adsorbed on to sorbent }} \times 100$

According to the analysis of outlet solution for desorbed nitrite ions, it was found that the desorption percentage was not satisfactory (less than 10\%). Poor desorption of nitrite anions can be denoted to strong interactions (e.g. electrostatic attraction) between nitrite ions and adsorbents (PPy or PAni), and partly might be due to redox reaction between the electroactive polymer and nitrite ion (a reducing chemical). It may be possible to improve regeneration or desorption percentage of nitrite ions from exhausted column using more suitable chemicals. In a separate experiment, when the partially regenerated columns were used for sorption of nitrite ion, only a little decrease in adsorption capacity of the polymers was observed.

\section{CONCLUSION}

Sawdust, an environmentally friendly and very low cost agricultural waste material was found to be a good substrate for coating by PPy and PAni polymers from aqueous solutions. By doping of conducting electroactive polymers such as polypyrrole and polyaniline with small and releasable anions such as $\mathrm{Cl}^{-}$, removal of nitrite ions is possible. Removal of nitrite ions using PPy and PAni is supposed to occur mostly via ion exchange process. However, the possibility of the other mechanisms can not be ignored. Further precise study is needed for achievement of more accurate conclusions. It was found that higher sorption of $\mathrm{NO}_{2}{ }^{-}$ion was observed at relatively acidic $\mathrm{pH}$ values, using both PPy/SD and PAni/SD. Among the examined adsorbents employed in this research, it was found that PPy/SD is more efficient for the removal of nitrite ions from aqueous solutions. The results obtained in this paper are promising for the practical application of currently introduced adsorbents for the re- moval of some toxic anions in the treatment of waste effluents.

\section{ACKNOWLEDGEMENTS}

The authors would like to acknowledge financial support from the Postgraduate Studies of University of Guilan. The authors are also thankful to the reviewers for their valuable comments and useful suggestions.

\section{REFERENCES}

[1] Boyd, C.E.; Tucker, C.S. Pond Aquaculture Water Quality Management, Kluwer, Academic Publishers: Boston, 1998.

[2] Campbell, M.; Dunn, A. Evidence on developmental and reproductive toxicity of Sodium nitrite, Environmental Protection Agency: California, 2000.

[3] Gómez, M.A.; González-López, J.; Hontoria-Garcia, E. Influence of carbon source on nitrate removal of contaminated groundwater in a denitrifying submerged filter. J. Hazar. Mat., 2000, B80, 6980.

[4] Lin, S.H.; Wu, C.L. Electrochemical removal of nitrite and ammonia for aquaculture. Water Res., 1996, 30(3), 715-721.

[5] Ansari, R.; Khoshbakht Fahim, N. Application of polypyyrole coated on wood sawdust for removal of $\mathrm{Cr}(\mathrm{VI})$ ion from aqueous solutions. React. Func. Polym., 2007, 67, 367-374.

[6] Ansari, R.; Delavar, A.F. Sorption of Silver Ion from Aqueous Solutions Using Conducting Electroactive Polymers. J. Iran. Chem. Soc., 2008, 5(4), 657-668.

[7] Wallace, G.G.; Spinks, G.M.; Kane-Maguire, L.A.P.; Teasdale, P.R. Conductivce Electroactive Polymers, Intelligent Materials Systems, Second ed.; CRC Press LLC: United States of America, 2003

[8] Guiseppi-Elie, A.; Wallace, G.G.; Matsue, T. Handbook of Conducting Polymers, Marcel Dekker: New York, 1998.

[9] Diaz, A.F.; Lacroix, J.C. Synthesis of electroactive/conductive polymer films: Electro-oxidation of heteroaromaticcompounds. $N$. J. Chem., 1988, 12, 171-182.

[10] Ansari, R. Electrochemical synthesis and characterization of polypyrrole conducting/electroactive polymers, Rus. J. Electrochem., 2005, 41(9), 950-956.

[11] Weidlich, C.; Mangold, K.M.; Juttner, K. Conducting polymers as ion-exchanger for water purification. Electrochem. Acta, 2001, 47 741-745.

[12] Ansari, R.; Price, W.E.; Wallace, G.G. Quartz crystal microbalance studies of the effect of solution temperature on the ion-exchange properties of polypyrrole conducting electroactive polymers. React. Func. Polym., 2003, 56, 141-146.

[13] Stejskal, J.; Gilbert, R.G. Polyaniline: Preparation of conducting polymer. Pure Appl. Chem., 2002, 74(5), 857-867.

[14] Ansari, R. Application of Polyaniline and its Composites with Conventional Polymers for Adsorption/Recovery of chromium hexavalent from aqueous solutions. Acta Chim. Slov., 2006, 53, 88-94.

[15] Vannacci, A.; Giannini, L.; Passani, M.B.; Felice, A.D.; Pierpaoli, S.; Zagli, G.; Fantappiè, O.; Mazzanti, R.; Masini, E.; Mannaioni, P.F. J. Pharmacol. Exper. Ther. Fast Forward, 2004, 311(1), 256264. 